\title{
Reply to M. Faye's objections to Mr. C. W. Siemens's theory of the sun
}

\section{C.W. Siemens}

To cite this article: C.W. Siemens (1882) Reply to M. Faye's objections to Mr. C. W. Siemens's theory of the sun, Philosophical Magazine Series 5, 14:90, 480-483, DOI: 10.1080/14786448208628448

To link to this article: http://dx.doi.org/10.1080/14786448208628448

曲 Published online: 28 Apr 2009.

Submit your article to this journal $[\pi$

Џll Article views: 2

Q View related articles $₫$ 
it; and I show that it would suffice if there were 1 kilogr. of matter in vapour in 700 thonsand millions of cubic metres-in other words, that the density would be $0.00000000000143 \mathrm{kilogr}$. It will be seen that we are far from the reduction to the $\frac{1}{200}$, and even to the millionth assumed by Mr. Siemens. If, instead of taking account only of the resistance opposed by such a gas to the motion of our planet, we direct our attention to the consequences which its existence would have upon that of our atmosphere, we find that, unless we multiply our 700 thousand millions of cubic metres by 10,000 , and reduce the density sought for to 0.0000000000000001 kilogr., our atmosphere would be in a few moments swept away by the pressure exerted abore by the interstellar gas.

M. Faye is perfectly justified in saying that it is not such or such a degree of rarefaction, but that it is the vacuum (of matter, of course) that the astronomer requires to ensure the stability of the movements that his analysis shows. This vacuum no doubt upsets the doctrine, supposed to be so undeniable, which ascribes all the phenomena of the physical world to movements and collisions of material atoms independent of each other. One day or another, no doubt, this doctrine will have to give up its existence, and its defenders will have to resign themselves to admit in the physical world something more than matter in motion. In a remarkable letter to Bentley, Newton said that one must be destitute of all aptitude for a serious philosophical discussion to suppose that between two bodies which seem to attract each other at an unlimited distance, there is not something which establishes this relation; but, he adds immediately, is this intermediary material or immaterial? This I leave to the reader to decide. With that great genius undoubtedly there was no uncertainty upon this latter point; but, perhaps justly, he refrained from putting before his contemporaries a solution which might have seemed incomprehensible to them, as it still is, apparently, to so many minds of the present day.-Comptes Remilus, November 6, 1882, p. 812.

REPLY TO M. FAYE'S OBJECTLONS TO MR. C. W. SIEMENS'S THEORY OF THE SUN, BY C, W.SIEMENS.

M. Faye, while approving, generally, of the physical part of my investigations, questions their application to astronomy, and for the following reasons:--

1. That the presence of a universal gaseous medium at a pressure of $\frac{1}{2000}$ atmosphere would oppose an excessive resistance to the movements of the planets; 2. That this vapour, thus distributed, would be gradually attracted towards the sun and would tend to angment its mass considerably.

Allow me to point out, as regards, in the first place, the second of M. Faye's objections, that the degree of diffusion supposed by me is such as may ensure the permanence of the statical equilibrium between the forces of expansion and diffusion on the one hand, and 
the attraction towards the sun and the celestial bodies ou the other. If no such equilibrium were established, M. Faye's objection would at once upset my theory. I am, moreover, inclined to admit that if Mariotte's law with regard to the tension of gases could be applied indefinitely, the pressure of the interplanetary gaseons medinm would be reduced almost beyond any thing of which we can form an idea; but it seems to me, from considerations drawn from the dynamical theory of gases, and from the manner in which, as demonstrated by $\mathrm{Mr}$. Crookes, gases behave when rarefied to an extraordinary degree in tubes-it seems to me, I say, that at least there exists no reason à priori why this law should be extended rigorously to vapours beyond the confines of our atmosphere and of that of the Sun.

As regards M. Faye's first objection, I admit that a density of I atmosphere would have the consequences which he so correctly establishes; and I remember having said (see 'Proceedings of the Royal Society,' p. 395) that assuming as demonstrated the results of my experiments on the dissociation of vapours by the solar energy, and that stellar space is filled with vapour at a pressure not exceeding the limit of $\frac{1}{1000}$ atmosphere, which corresponds to the highest rarefaction that I was able to obtain in my experiments, a dissociation of this cosmical vapour must ensue by the radiation of the Sun. It must nevertheless be remarked that this observation only relates to the physical phenomena submitted to my experiments, and that it is evident that if, the dissociation of aqueous vapour and of carbon-compounds is effected by the direct radiation of the sun at so high a pressure as $\frac{1}{1000}$ atmosphere, it would with still more reason be effected in the much more rarefied medium.

In another passage of my memoir (p. 397), when I apply my bypothesis to comets, I assume that, even at their perihelion, they represent a vapour-medium with a density of only $\frac{1}{3000}$ atmosphere, and that this density suffices to give rise to incandescence by compression. This supposition proves, at any rate indirectly, that I regarded stellar space as filled with vapour at a pressure much below $\frac{1}{3000}$ atmosphere, while still speaking of this medium (in the absence of all data of experiment and observation) as in an extremely rarefied state, without fixing any limit of this rarefaction.

Since then new facts of observation have teuded to confirm my hypothesis of a stellar space filled with rarefied matter analogous to that which we can actually produce in our vacuum-tubes. The equatorial prolongations of the solar atmosphere observed in America during the eclipse of 1859 , seem to demonstrate the existence of matter extending from the Sun for several millions of leagues, and rendered visible, no doubt, by solid particles, illuminated partly by the reflection of the solar light, and partly by discharges of electricity towards the Sun.

My hypothesis has found a still more direct confirmation in the remarkable spectroscopic investigations communicated by Capt. Abney to Section A of the British Association in the month of August last, which demonstrate that carbon-compounds, probably

$$
\text { Phil. Mag. S. 5. Vol. 14. No. 90. Dec. 1882. } 2 \mathrm{~K}
$$


analogous to ethyl, easy to observe distinctly, exist, and at a low temperature, between the Sun's atmosphere and our own. The observations made in America by Prof. Langley with his bolometer, although made for a totally different purpose, tend to confirm the results obtained by Capt. Abney upon the Riffel. We may also add to these pronfs the interesting observation of Prof. Schwedoff (still unpublished, and communicated to me on the same occasion by Prof. Silvanus Thompson), according to which large hailstones of cosmical origin have sometimes fallen upon the earth. This observation, however, needs to be confirmed.

Accepting these observations as founded upon facts, physical considerations are not wanting for the approximate determination of the actual density of the stellar vapour, which, in this case, is only a function of the temperature of space. As Gorschow, on 30 th November 1871 , observed a temperature of $-63^{\circ} \mathrm{C}$. in the Arctic regions, it follows that the stellar medium (which, if it consists of a vapour, must be able to intercept calorific rays) must be at a temperature comprised between $-63^{\circ}$ and the absolute zero $\left(-273^{\circ}\right)$; the solar radiation must maintain in it some temperature, or, at least, such a temperature that the dissociation of this medium is very active.

It is to Regnault that we owe our most exact knowledge of the density of vapours at different temperatures; but his researches did not extend below $-32^{\circ} \mathrm{C}$., and his formulæ cannot be rigorously applied below that point; nevertheless they enable us to estimate approximately what may be the densities of a vapour at lower temperatures; and it is thus that we are led to believe that at $-130^{\circ}$ the density of aqueous vapour does not exceed $\frac{1}{5,000,000}$ atmosphere. If we assume, further, that the gaseous mass which fills space contains only $\frac{1}{5}$ of aqueous vapour, the other four fifths being composed of hydrocarbons, carbonic acid, and nitrogen, the total pressure of the vapour would not exceed $\frac{1}{1,000,000}$ atmosphere.

These vapours would traverse space with a velocity equal, probably, to half the tangential velocity at the surface of the Sun, or at about 1 kilometre per second. It would be easily demonstrated that a column of these dissociated gases travelling with this velocity towards the polar surfaces of the sun and taken at a distance of $5,500,000$ kilom. from the Sun (equal to the mean distance of Mercury, the nearest of his planets) would present a section of flow towards the Sun equal to 140,000 milliards of square kilometres, much more than sufficient to furnish the material necessary to yield by combustion the heat required to maintain the solar radiation.

Perhaps the eminent Director of the Bureau des Longitudes may be inclined to think that a gaseous medium of a density equal at most to $\frac{1}{1,000,000}$ of that of our atmosphere might still interfere with planetary movements to a degree incompatible with the facts ascertained by astronomical observations. If this be the case, it would suffice to assume a still lower temperature for this medium, 
and in consequence a more attenuated rarefaction of the interstellar gaseous matter.-Comptes Rendus de l'Académie res Sciences, Oct. 30, 1882, p. 769.

\section{ON A PROPERTY OF THE COEFFICIENT OF ABSORPTION. BY EILHARD WIEDEMANN.}

Bunsen represents the absorption-coefficient $a$ at a temperature $t$ by the formula

$$
\alpha=a-b t+c t^{2}
$$

in which $a$ and $b=$ a constant.

Instead of this, we can write

$$
\alpha=a\left\{1-\frac{b}{a} t+\frac{c}{a} t^{2}\right\}
$$

In the following Table I have set down, together with the values of $a, b \cdot 10^{6}$, and $c \cdot 10^{7}$, the values of $b / a$ and $c / a$ for a series of

\begin{tabular}{|c|c|c|c|c|c|}
\hline & $a$. & $b$. & $c$. & $\frac{b}{a}$ & $\frac{c}{a}$ \\
\hline Hydrogen ..... & 0.0193 & 0 & 0 & 0 & 0 \\
\hline Nitrogen .. & 0.0203 & 539 & 112 & 0.02648 & $0 \cdot 000548$ \\
\hline Air ........ & 0.0247 & 654 & 135 & 0.026487 & 0.000548 \\
\hline Diethyl ........... & 0.0315 & 1045 & 251 & 0.033198 & 0.000796 \\
\hline Carbonic oxide. & 0.0329 & 816 & 164 & 0.0243 & 0.000499 \\
\hline Oxygen .......... & 0.0412 & 1089 & 226 & 0.02648 & 0.00054 \\
\hline Marsh-gas & 0.0545 & 1180 & 103 & $0 \cdot 02166$ & 0.00018 \\
\hline Dimethyl ........... & 0.0871 & 3324 & 603 & $0 \cdot 03816$ & 0.00069 \\
\hline Hydride of ethyl ..... & $0 \cdot 0946$ & 3532 & 628 & 0.03735 & 0.000663 \\
\hline Ethylene ............ & 0.2563 & 9136 & 1881 & $0 \cdot 03564$ & 0.000654 \\
\hline Propylene .................... & 0.4465 & 22075 & 5388 & $0 \cdot 04943$ & 0.000206 \\
\hline Nitrous oxide $\ldots . . . . . \ldots .$. & 1.3052 & 45362 & 6483 & $0 \cdot 03475$ & 0.00049 \\
\hline Carbonic acid $\ldots . . \ldots \ldots$ & $1 \cdot 7967$ & 77610 & 16424 & 0.04320 & 0.000914 \\
\hline Sulphuretted hydrogen. & 43706 & 83687 & 5213 & 0.01914 & $|0 \cdot 100119|$ \\
\hline Sulphurous acid .... & $79 \cdot 789$ & 2607700 & 263490 & 0.03268 & 0.000367 \\
\hline Chlorine............. & $3 \cdot 0361$ & 46196 & 1107 & & \\
\hline
\end{tabular}
gases and water :-

It will be remarked that the values of $b / a$ in this Table vary only from 0.02 to 0.05 , while $a$ itself ascends from 0.02 to 79.789 , i. $e$. up to 4000 times the former value. But the values of $b / a$ indicate how large a fraction of the gas absorbed at $0^{\circ}$ escapes on the temperature being raised $1^{\circ}$; and from the above it follows that that fraction varies within very narrow limits for all gases.

In order to further test this proposition, it would be necessary to institute experiments for larger intervals of temperature.

A comparison of the absorptions in alcohol gave similar results. -Wiedemann's Annalen, vol. xvil. p. 349 (1882). 